\title{
Investigation of Soil Salinity to Distinguish Boundary Line between Saline and Agricultural Lands in Bonab Plain, Southeast Urmia Lake, Iran
}

\section{*11NIKOU, HAMZEHPOUR; MEHDI, RAHMATI}

\author{
${ }^{1,2}$ Department of Soil Science, Faculty of Agriculture, University of Maragheh, Maragheh, Iran \\ *Corresponding author:nhamzehpour@maragheh.ac.ir \\ Address: Postal Code: 55181-83111, Maragheh, Iran. Office Phone: +984137273070 Office Fax: +984137276060
}

\begin{abstract}
Gradual drying of Urmia Lake has left vast saline areas all around it, increasing the risk of salinization of agricultural lands next to the Lake. The current research was aimed to predict soil salinity and distinguish the boundary line between saline and agricultural lands by taking in to account the spatial variability of soil salinity in Bonab Plain, Iran. To do so, soil samples were taken from depth $0-25 \mathrm{~cm}$ in 78 points with spatial intervals of $500 \mathrm{~m}$ and were analyzed for their electrical conductivity in saturated paste extractions. Data analysis showed that soil salinity mean wasn't stationary and was varying among dataset. Therefore to build up a variogram, the spatial components of the mean trend were computed and subtracted from laboratory measured $\mathrm{EC}_{\mathrm{e}}$ values, which resulted in residuals. The semivariogram function was then calculated and modelled based on the residuals. Cross-validation results showed that kriging method along with modified semi-variogram, resulted in better predictions of soil salinity with ME and MSE equal to 0.12 and 0.3 . Setting $4 \mathrm{dSm}^{-1}$ as the limit between saline and non-saline soils in kriging algorithms resulted in a sharp boundary line between saline and non-saline lands in the study area. The presence of highly saline soils next to the agricultural lands in the area can increase the risk of secondary salinization of the Bonab Plain which is one of the important agricultural production centers in the area. Therefore, careful monitoring of lands near salinity boundary in the area should be of high priority. () JASEM
\end{abstract}

http://dx.doi.org/10.4314/jasem.v20i4.16

Key Words: Bonab Plain, Kriging, variogram, soil salinity, spatial prediction, Urmia Lake.

Population growth along with limited agricultural lands in the world has been one of the most important challenges of food production during few past decades. On the other hand, land quality reduction as a consequence of unsound management practices resulted in unsustainable agricultural yields (FAO, 2007).

The Urmia Lake is located in the northwest of Iran. It is the second largest salty lake in the world with a total extent of $5822 \mathrm{Km}^{2}$ (Karbasi et al., 2010). Urmia Lake basin is important agricultural production areas with a population of 6.4 million whose livelihoods are mostly depend on agricultural activities (Jalili et al., 2011). There are several highly productive Plains all around the Lake. Over the recent years, the lake has been drying up at a fast pace due to unrestrained withdrawal of water from the main rivers entering the lake, climatic change, and low rainfall (Mohebi and Emanifar, 2007). As of shallow depth of Urmia Lake, its drying has resulted in its total area shrink, remaining vast saline lands around it (Golabian, 2011).

In such saline lands, agriculture seems to be impossible and many of the native plant species may not be able to grow. On the other hand, through time, Playa surfaces are developing in the area some of which are susceptible to wind erosion and capable of dust productions. In similar case, drying of Aral Lake which is located $1200 \mathrm{~km}$ from east of Urmia Lake, resulted in salt storms leading to salinization of the agricultural lands and several unsolved environmental, ecological and social issues (Golabian, 2011).

Therefore, the trend and rate of soil salinity and alkalinity changes in adjacent Plains of Urmia Lake require careful monitoring and management. However, intense sampling campaigns are needed due to the high variability of soil salinity. On the other hand, samplings at different time instants are also required for monitoring the temporal changes of salinity. Performing such an extensive field investigation is costly and time consuming. Over the last years, attempts have thus been made to reduce the number of samples by using geostatistical methods while at the same time, making a better use of measurements.

During past decades, spatial prediction methods such as kriging methods have played significant role in both reducing the number of samples necessary to monitor a large area and also data gathering expenses. Recent improvements in the field of geostatistics and advances in calculating complex problems have made the analysis of variables with spatial correlation possible. Kriging methods have widespread use in geostatistical methods and in soil salinity prediction models which have been discussed 
in detail in several papers (Li and Heap, 2008). There have been numerous attempts in mapping spatial variability of soil electrical conductivity (EC) using kriging methods (Peck and Hatton, 2003; Triantafilis et al., 2004; Malins and Metternicht, 2006; de Clercq et al., 2009; Giordano et al., 2010; Acosta et al., 2011; Li et al., 2011). The aim of present study was to investigate the spatial variation of soil salinity and to distinguish the boundary line between saline and agricultural lands in Bonab Plain, southeast Urmia Lake by taking into account spatial mean variation throughout the study area.

\section{MATERIAL AND METHODS}

Study site: The study area is located in Bonab Plain with an elevation of $1270-1300 \mathrm{~m}$, in the northwest of Iran. About $40 \mathrm{~km}^{2}$ of land with different degrees of salinity were selected. The corresponding area is located between $45^{\circ} 58^{\prime} 41^{\prime \prime}$ to $46^{\circ} 02,35^{\prime \prime} \mathrm{E}$ and $37^{\circ}$ 20 ' $21^{\prime \prime}$ to $37^{\circ} 16^{\prime} 18^{\prime}$ ' N (Figure 1 ). The mean annual precipitation is $264.73 \mathrm{~mm}$. The mean annual temperature is $15^{\circ}$. Potential evaporation in the area is between 900-1170 mm. geologically, the study area is composed of playa and alluvial deposits.

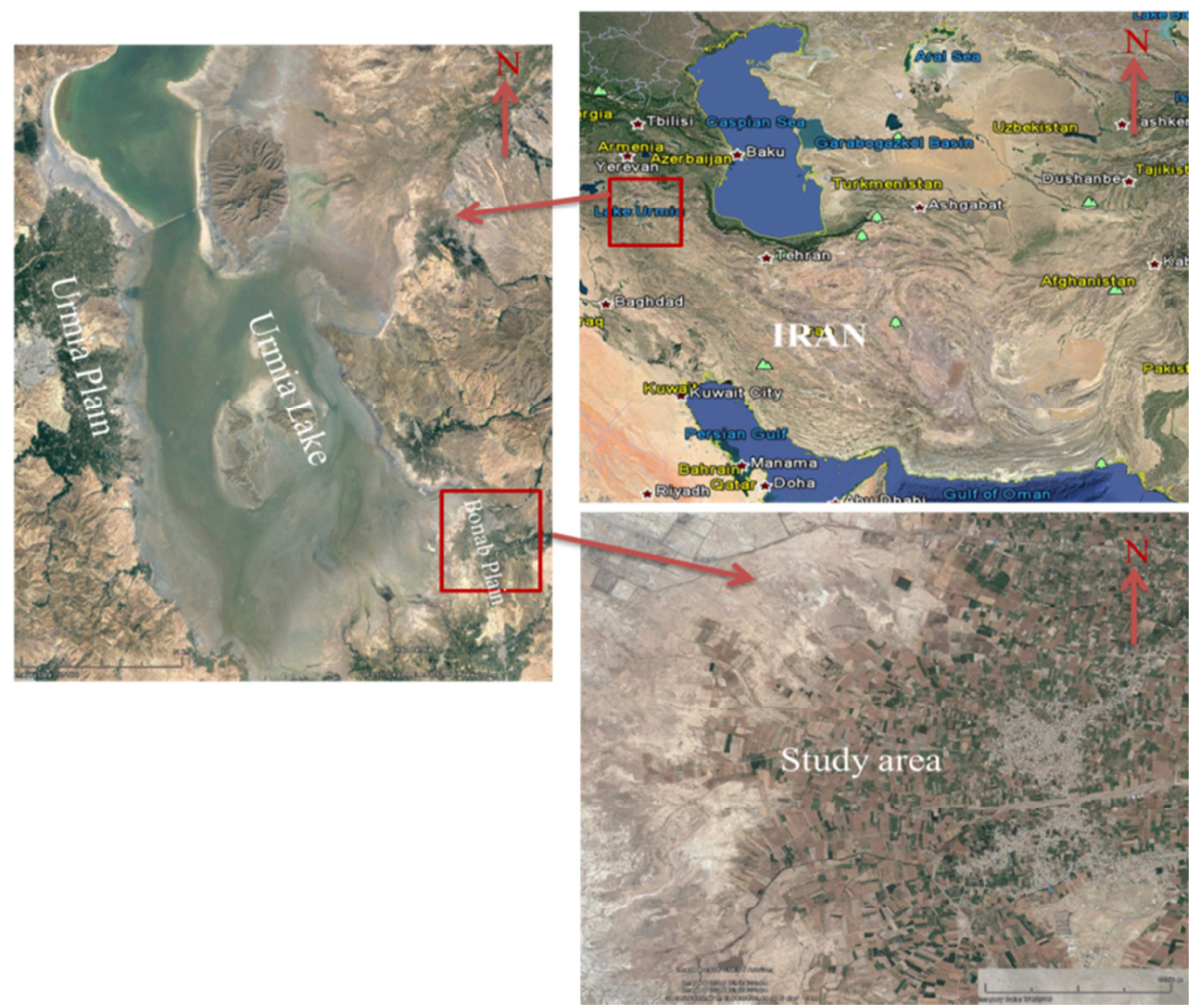

Fig 1: The study area in the southestern part of Uromieh Lake in Bonab Plain.

Data description: Sampling for soil salinity measurement was done on a 500 meter grid which covers the $40 \mathrm{~km}^{2}$ of the study area. 78 samples were collected during autumn 2014. Saturation paste soil electrical conductivity (ECe) was measured at a depth of $0-25 \mathrm{~cm}$ in the laboratory using a Jenway 4510 bench conductivity meter.
Statistical analysis: Kriging estimators' basic equation is defined as follows (Li and Heap, 2008):

$$
Z\left(x_{0}\right)-\mu=\sum_{i=1}^{n} \lambda_{i}\left[Z\left(x_{i}\right)-\mu\left(x_{0}\right)\right]
$$

Where $\mu$ is an acknowledged stationary mean of the variable, $Z_{1}\left(x_{i}\right)$ is the data at point $i, \mu\left(x_{0}\right)$ is the mean of samples within the search window, $n$ is the 
number of sample points within the search window, $\left(\lambda_{i}\right)$ is the weight selected to minimize the estimation variance of the variable.

Validation and comparison criteria: To compare the results using cross-validation procedure, soil salinity was predicted at each location for which we had measurements by deleting the value of each location in turn, where the prediction was made. This resulted in pairs of estimated-observed soil salinity. From these pairs of values, two global performance criteria were computed: the mean error (ME) and the mean squared error (MSE). Accurate predictions are thus characterized by a ME and MSE values close to zero. All the analyses were done using the BMElib toolbox (Christakos and Serre, 2000) in Matlab (MathWorks, 1999).

\section{RESULTS AND DISCUSSIONS}

Data analysis: Color Plot for sampling campaign is presented in Figure 3a. Table 1 provides summary statistics for top soil salinity measurements. Maximum and minimum measured soil salinity values for autumn 2014 were 141.5 and $0.41 \mathrm{dSm}^{-1}$ with a mean value of $22.07 \mathrm{dSm}^{-1}$. Although we expected soil salinity to show gradual and joint variations in space through study area since it seems to be a continuous variable, there was a large variations of soil salinity within relatively small distance. In other words, soil salinity increased from $1 \mathrm{dSm}^{-1}$ or less to higher than $20 \mathrm{dSm}^{-1}$ in very small distances. This phenomenon was observed all over the study are, parallel to Urmia Lake. This has been reported previously by Hamzehpour and Eghbal (2016) in the western shore of Urmia Lake where the maximum spread of Urmia Lake had drawn a narrow boundary between saline soils and agricultural lands. Therefore, analyses were done on logarithmically transformed $\mathrm{EC}_{\mathrm{e}}$ due to the typical skewness exhibition by EC distributions (Table 1).

Table1: Summary statistics of top soil salinity $\left(\mathrm{dSm}^{-1}\right)$ in 78 sampling locations in southeast Urmia Lake in Bonab Plain.

\begin{tabular}{lllcclll}
\hline $\mathbf{E C}_{\mathbf{e}}\left(\mathbf{d S m}^{-1}\right)$ & $\mathbf{N}$ & Mean & Standard deviation & Min & Max & Skewness & Kurtosis \\
\hline & 78 & 22.07 & 7.42 & 0.41 & 141.5 & 1.67 & 1.97 \\
\hline
\end{tabular}

Semi-variogram function:

Due to the nature of the dataset, mean soil salinity, varied between saline and nonsaline areas. In order to assess the spatial variability of the data, taking into account the mean variation among dataset, the spatial components of the mean trend were computed and subtracted from laboratory measured $\mathrm{EC}_{\mathrm{e}}$ values, which resulted in residuals. The semi-variogram function was then calculated and modelled based on the residuals (Figure 2).

Isotropic Variogram

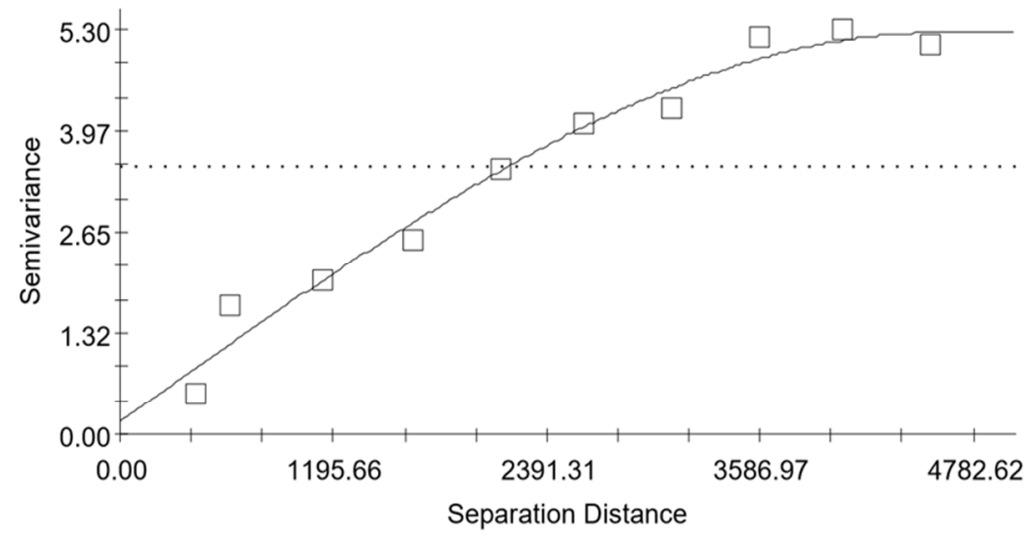

Fig 2: Spatial semi-variogram function for laboratory measured soil salinity during autumn 2014. Dots correspond to calculated values; solid line is the corresponding fitted model. 
The fitted semi-variogram model had two parts: a nugget effect equal to $0.16\left(\mathrm{dSm}^{-1}\right)^{2}$ and a spherical part, with a range of $4580 \mathrm{~m}$ and a sill of $5.25\left(\mathrm{dS} \mathrm{m}^{-1}\right)^{2}$. Resulted semi-variogram was used in spatial prediction of soil salinity on a grid of 100 meters.

Salinity map resulted from spatial prediction of soil salinity using 78 laboratory measured soil samples is presented in Figure 3b. According to Figure 3b, using a unified variogram with removed effect of spatial variation of soil salinity mean throughout the study area, resulted in convincing predictions.
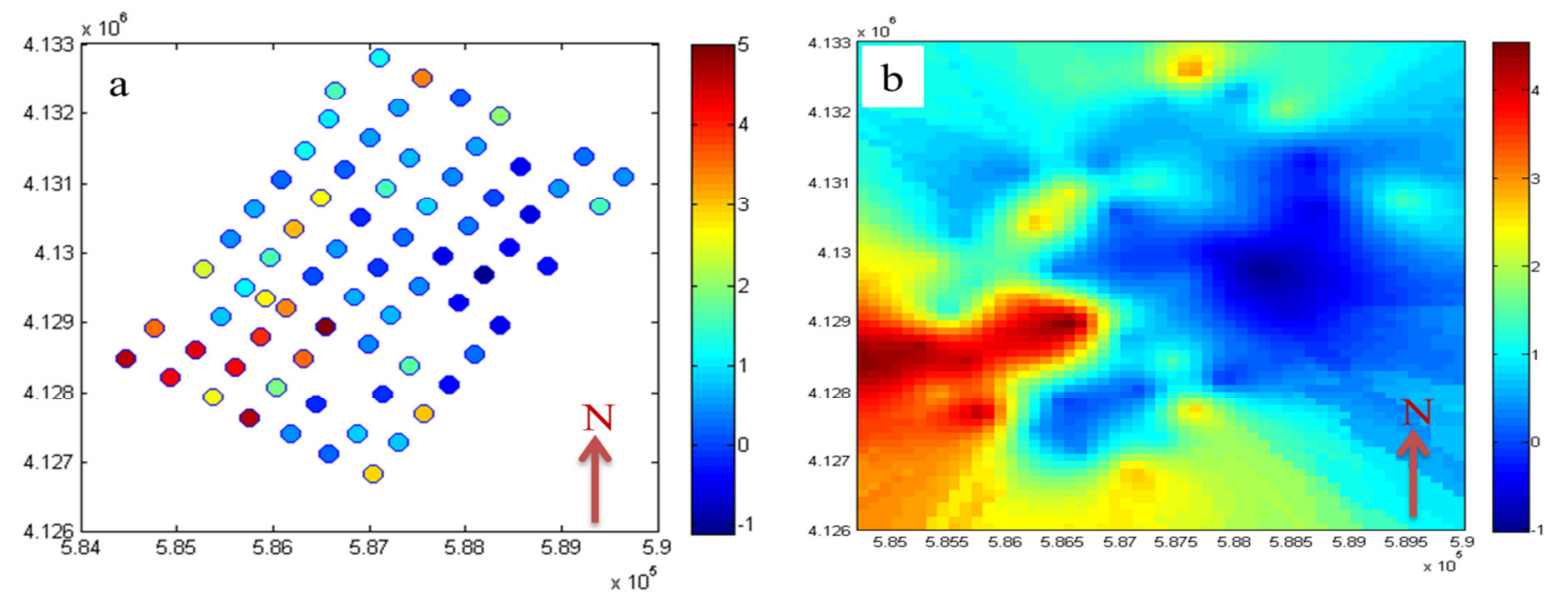

Fig 3: Plots for the sampling campaign. The level of colour reflects the top soil measured $\mathrm{EC}_{\mathrm{e}}$ values in $\mathrm{dSm}^{-1}$ on the field in log scale. b: spatial prediction of top soil salinity in Bonab Plain using fitted semi-variogram function.

Taking in to acount parts a and $\mathrm{b}$ in Figure 3 reveals that using modified semi-variogram in areas with large mean variations could successfully be used in spatial prediction of soil salinity. Hamzehpour et al., (2013) also used a modified covariance function after removing the spatial variation of mean effect from the dataset.

Cross-validation results with ME and MSE of 0.12 and 0.3 respectively, showed that kriging method by taking into account mean variation in the study area could successfully be used in spatial prediction of soil salinity (Figure 4a).

Later in order to estimate the boundary between saline and agricultural lands in the study area, salinity of $4 \mathrm{dSm}^{-1}$ were set as a threshold between saline and non-saline soils (Weil and Bradly, 2016) in spatial prediction algorithms embedded in BMElib software codes. Afterwards spatial prediction of soil salinity was done once more on a grid of 100 meters. Results from spatial prediction of soil salinity boundary are presented in Figure $4 \mathrm{~b}$. Red color represents the saline areas (equal to or higher than $4 \mathrm{dSm}^{-1}$ ) and blue belongs to non-saline areas (less than $4 \mathrm{dSm}^{-1}$ ).

According to the results, there is a narrow boundary between saline and agricultural lands in the southeast Urmia Lake which could be mapped successfully using kriging algorithms embedded in BMElib software, by taking into account mean variation. Presence of highly saline soils next to the agricultural lands in the study area is a potential treat to sustainable agriculture which is growing with a high speed since the Urmia Lake has been drying and its shores are withdrawing. The same results were reported by Hamzehpour et al., $(2013 ; 2015)$ and Hamzehpour and Eghbal (2016) from their study area in West of Urmia Lake. However, soil salinity seems to be a bigger problem in the Bonab Plain in the southeast of Urmia Lake rather than western shores, as according to the reports, mean soil salinity in lands next to the Urmia Lake in its western shore was 4 $\mathrm{dSm}^{-1}$ (Hamzehpour et al., 2013) but, according to the findings of the present research, mean soil salinity in southeast shore of Urmia Lake is $22 \mathrm{dSm}^{-1}$. 

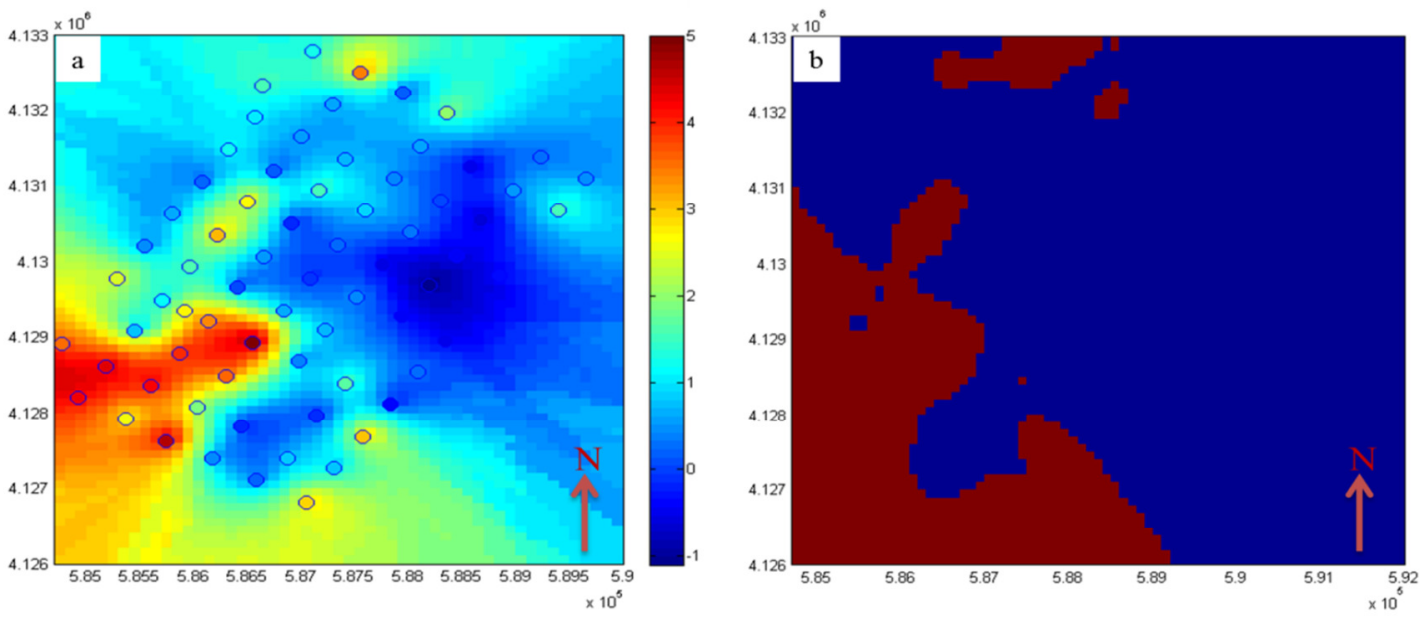

Fig 4: spatial prediction of top soil salinity with validation points in Bonab Plain using fitted semi-variogram function. b: spatial prediction of boundary between saline and agricultural lands. Blue represents soils with salinity lower than $4 \mathrm{dSm}^{-1}$ and red represents soils with salinity higher than $4 \mathrm{dSm}^{-1}$.

Conclusion: In this study we tried to map the soil salinity boundary line in Bonab Plain, southeast Urmia Lake, Iran. 78 soil samples were gathered on a grid of 500 meters and they were analyzed for their EC in saturated paste extracts. To build up a variogram, the spatial components of the mean trend were computed and subtracted from laboratory measured $\mathrm{EC}_{\mathrm{e}}$ values, which resulted in residuals. The semi-variogram function was then calculated and modelled based on the residuals. Then soil salinity prediction was done on a grid of 100 meters. After data validation, by defining soil salinity of $4 \mathrm{dSm}^{-1}$ in kriging algorithms as the limit between saline and non-saline soils, boundary line between saline and agricultural lands was estimated. Results revealed that there is a relatively narrow boundary line between saline and agricultural lands in the study area, where abrupt and major soil salinity variations are happening. The presence of such highly saline soils next to the agricultural lands is great danger for sustainable agricultural production in the area, where economy of the society mainly depends on agriculture. Therefore proper actions should be considered before secondary salinization of the productive agricultural lands occurs.

\section{REFERENCES}

Acosta, JA; Faz, A; Jansen, B; Kalbitz, K; MartinezMartinez, S (2011). Assessment of salinity status in intensively cultivated soils under semiarid climate, Murcia, SE Spain. J. Arid Environ. 75: 1056-1066.
Christakos, G; Serre, ML (2000). BME analysis of spatiotemporal particulate matter distributions in North Carolina. Atmos. Environ., 34:3393-3406.

De Clercq, WP; Van Meirvenn, M; Fey, MV (2009). Prediction of the soil-depth salinity-trend in a vineyard after sustained irrigation with saline water. Agric. Water Manage. 96: 395-404.

Douaoui, AEK; Nicolas, H; Walter, Ch (2006). Detecting salinity hazards within a semiarid context by means of combining soil and remotesensing data. Geoderma, 134:217-230.

FAO (2007). Extent and Causes of salt-affected soils in participating countries. AGL: Global Network on Integrated Soil Management for Sustainable use of Salt affected soils. http://www.fao.org/ag/agl/agll/spush/topic2.htm.

Giordano, R; Liersch, S; Vurro, M; Hirsch, D (2010). Integrating local and technical knowledge to support soil salinity monitorinf in the Amudarya river basin. J. Environ. Manage. 91: 1718-1729.

Golabian, H. (2010). Urumia Lake: Hydro-Ecological Stabilization and Permanence Macro-engineering Seawater in Unique Environments (pp. 365-397). Berlin: Springer-Verlag. doi: 10.1007/978-3642-14779-1_18.

Hamzehpour, N; Eghbal, MK (2016). Spatiotemporal prediction of soil salinity boundary using kriging with measurement errors. Eco. Env. Cons. 22(3):57-67. 
Hamzehpour, N; Eghbal, MK; Toomanian, N; Oskoui, RS; Bogaert, P (2015). Uncertainty Assessment of the Soil Salinity Boundary in Uromia Plane Using Bayesian Maximum Entropy Method. J. Soil Manag. Sustain. Agri. 5(2): 131-147.

Hamzehpour, N; Eghbal, MK; Bogaert, B; Toomanian, N; Oskoui, RS (2013). Spatial prediction of soil salinity using kriging with measurement errors and probabilistic soft data. Arid Land Res. Manag. 27 (2): 128-139.

Karbassi, A; Bidhendi, G; Pejman, A; Bidhendi, M (2010). Environmental impacts of desalination on the ecology of Lake Uromia. J. Great Lakes Res. 36(3):419-424.

Jalili, S; Kirchner, I; Livinstone, DM; Morid, S (2011). The influence of large-scale atmospheric circulation weather types on variations water level of Lake Uremia. Published online in Wiley online Library.

Li, KL; Chen, J; Tan, MZ; Zhao, BZ; Mi, SX; Shi, XZ (2011). Spatio-Temporal variability of soil salinity in Alluvial Plain of the lower reaches of the Yellow River- a case study. Pedosphere. 21(6): 793-801.

Li, J; Heap, AD (2008). A Review of Spatial Interpolation Methods for Environmental Scientists. Geoscience Australia, Canberra, Australia.

Malins, D; Metternicht, G (2006). Assessing the spatial extent of dryland salinity through fuzzy modeling. Ecol. Model. 193: 387-411.
Marlet, S; Bouksila, F; Bahri, A (2009). Water and salt balance at irrigation scheme scale: A comprehensive approach for salinity assessment in a Saharan oasis. Agric. Water Manage. 96:1311-1322.

Math Works Inc (1999). MatLab, the language of technical computing, using MATLAB version 5. the Mathwork Inc. http://www.mathworks.com, Natick.

Mohebbi, F; Eimanifar, A (2007). Uromia lake (North West Iran) a brief review. Licensce Biomed Central Ltd.

Mondal, MK; Bhuiyan, SI; Franco, DT (2001). Soil salinity reduction and prediction of salt dynamics in the coastal ricelands of Bangladesh. Agric. Water Manage. 47:9-23.

Peck, AJ; Hatton, T (2003). Salinity and the discharge of salts from catchments in Australia $J$. Hydrol. 272: 191-202.

Stein, A; Corsten, LCA (1991). Universal kriging and cokriging as a regression procedure. Biometrics. 47: 575-587.

Triantafilis, J; Odeh, IOA; Warr, B; Ahmed, MF (2004). Mapping of salinity risk in the lower Namoi valley using non-linear kriging methods. Agric. Water Manage. 69, 203-231.

Weil, RR; Brady, N C (2016). The nature and properties of soils, $15^{\text {th }}$ edition. Prentice-Hall Inc. ISBN-13: 978-0-13-325448-8. 